\title{
Vascular Endothelial Growth Factor (VEGF) isoform expression and activity in human and murine lung injury
} Andrew RL Medford ${ }^{1}$, Samantha K Douglas ${ }^{1}$, Sofia IH Godinho', Kay M Uppington ${ }^{1}$, Lynne Armstrong ${ }^{1}$, Kathleen M Gillespie ${ }^{1}$, Berendine van Zyl $^{1}$, Terry D Tetley ${ }^{2}$, Nassif BN Ibrahim ${ }^{3}$ and Ann B Millar*1

\begin{abstract}
Address: ${ }^{1}$ Department of Clinical Science at North Bristol, University of Bristol Paul O'Gorman Lifeline Centre, Southmead Hospital, Westburyon-Trym, Bristol, BS10 5NB, UK, ${ }^{2}$ Lung Cell Biology, National Heart \& Lung Institute, Imperial College, Dovehouse Street, London, SW3 6LY, UK and ${ }^{3}$ Department of Pathology, North Bristol NHS Trust, Frenchay Hospital, Frenchay Park Road, Frenchay, Bristol, BS16 1LE, UK

Email: Andrew RL Medford - andrewmedford@hotmail.com; Samantha K Douglas - samantha.douglas@bristol.ac.uk; Sofia IH Godinho - sofia.godinho@bristol.ac.uk; Kay M Uppington - kay.uppington@bristol.ac.uk;

Lynne Armstrong - lynne.armstrong@bristol.ac.uk; Kathleen M Gillespie - K.M.Gillespie@bristol.ac.uk; Berendine van

Zyl - Berendine.vanZyl@bristol.ac.uk; Terry D Tetley - t.tetley@imperial.ac.uk; Nassif BN Ibrahim - Nassif.Ibrahim@nbt.nhs.uk;

Ann B Millar* - Ann.Millar@bristol.ac.uk

* Corresponding author
\end{abstract}

Published: 9 April 2009

Respiratory Research 2009, 10:27 doi:10.1186/1465-9921-10-27

This article is available from: http://respiratory-research.com/content/10/1/27

(c) 2009 Medford et al; licensee BioMed Central Ltd.

This is an Open Access article distributed under the terms of the Creative Commons Attribution License (http://creativecommons.org/licenses/by/2.0), which permits unrestricted use, distribution, and reproduction in any medium, provided the original work is properly cited.
Received: 23 September 2008

Accepted: 9 April 2009

\begin{abstract}
Background: The properties of vascular endothelial growth factor (VEGF) as a potent vascular permogen and mitogen have led to investigation of its potential role in lung injury. Alternate spliced VEGF transcript generates several isoforms with potentially differing functions. The purpose of this study was to determine VEGF isoform expression and source in normal and ARDS subjects and investigate the expression and regulation of VEGF isoforms by human alveolar type 2 (ATII) cells.
\end{abstract}

Methods: VEGF protein expression was assessed immunohistochemically in archival normal and ARDS human lung tissue. VEGF isoform mRNA expression was assessed in human and murine lung tissue. Purified ATIl cells were cultured with proinflammatory cytokines prior to RNA extraction/ cell supernatant sampling/proliferation assay.

Measurements and Main Results: VEGF was expressed on alveolar epithelium, vascular endothelium and alveolar macrophages in normal and ARDS human lung tissue. Increases in VEGF expression were detected in later ARDS in comparison to both normal subjects and early ARDS $(\mathrm{p}<0.00 \mathrm{I})$. $\mathrm{VEGF}_{121}, \mathrm{VEGF}_{165}$ and $\mathrm{VEGF}_{189}$ isoform mRNA expression increased in later ARDS ( $\mathrm{p}$ $<0.05$ ). The ratio of soluble to cell-associated isoforms was lower in early ARDS than normal subjects and later ARDS and also in murine lung injury. ATII cells constitutionally produced VEGF I65 $_{165}$ and VEGF ${ }_{121}$ protein which was increased by LPS $(p<0.05)$. VEGF ${ }_{165}$ upregulated ATII cell proliferation $(p<0.00 I)$ that was inhibited by soluble VEGF receptor I $(s f t)(p<0.05)$.

Conclusion: These data demonstrate that changes in VEGF isoform expression occur in ARDS which may be related to their production by and mitogenic effect on ATII cells; with potentially significant clinical consequences. 


\section{Introduction}

Functional and physical failure of the alveolar capillary membrane is a pivotal event in the development of lung injury, exemplified by the acute respiratory distress syndrome (ARDS)[1]. The characteristics of vascular endothelial growth factor (VEGF), as both an angiogenic and permogenic factor has led to interest in its potential role in this condition[2,3]. It is known that VEGF protein is compartmentalized within the lung [4] and alveolar type 2 epithelial (ATII) cells have been identified as a major source of VEGF in both animal studies and human foetal lung studies[5,6]. Observational data show plasma VEGF levels rise and intrapulmonary (ie, measurable in the epithelial lining fluid (ELF) obtained by broncho-alveolar lavage) levels fall in the early stages of lung injury with normalization of both during recovery[7,8]. These changes in intrapulmonary VEGF have been confirmed in ARDS but have also been observed in other conditions in which alveolar injury may occur, such as high-altitude pulmonary oedema [9-11]. To explore the significance of these observations, it is necessary to understand the mechanisms that regulate VEGF bioactivity.

Alternative splicing of the VEGF transcript from exons 5 to 8 leads to the generation of several different isoforms with variable diffusibilities depending on their length: $\mathrm{VEGF}_{121}, \mathrm{VEGF}_{165}, \mathrm{VEGF}_{189}$ being the main forms[3,1214]. Exon 6 (not present in $\mathrm{VEGF}_{121}$ and $\mathrm{VEGF}_{165}$ ) and exon 7 provide heparin-binding affinity, exon 8 (present in all active isoforms) is necessary for the stimulation of mitosis[15]. The longer isoforms are highly basic and remain virtually completely cell-associated, whereas VEGF $_{121}$ (lacking both exons 6 and 7 ) is freely diffusible[14]. VEGF ${ }_{165}$ (lacking exon 6 but not 7) possesses intermediary properties being largely soluble but a distinct fraction remains cell-associated[14]. It is the predominant isoform and most biologically active in the physiological state[15].

Recovery from lung injury/ARDS requires functional/ physical repair of the alveolar epithelial surface to occur. ATII cells proliferate and differentiate into alveolar epithelial type 1 (ATI) cells to regenerate the alveolar epithelium after injury[16]. Limited and conflicting data exists on the effect of VEGF on alveolar epithelial proliferation; fetal human lung cells $[17,18]$ and pulmonary adenocarcinoma derived cell lines proliferate[19], whereas adult rat ATII cells do not[20]. There are no similar studies of adult human lung epithelial cells.

We initially hypothesised that changes in VEGF intrapulmonary levels observed by ourselves and others would be reflected in whole lung tissue and associated with changes in VEGF isoforms in ARDS lung which differ in early and late stages of the disease. We further hypothesised that the role of VEGF in the lung may be as an epithelial mitogen integral to lung repair. We have explored this hypothesis and additionally considered the effects of known inflammatory mediators, previously suggested to be involved in the pathogenesis of ARDS, in these processes.

\section{Methods \\ Specimens}

Archival normal and ARDS lung tissue sections and paraffin blocks for which consent for research had been obtained, were utilized for immunohistochemistry (ARDS had been histopathologically confirmed and groups divided into either "early ARDS" within 48 hours or "later ARDS" after day 7). ARDS had been diagnosed according to the internationally used 1994 American-European Consensus Conference criteria[21]. Isolation of ATII cells was undertaken from macroscopically normal lung tissue sections ( $15 \times 5 \times 5 \mathrm{~cm}$ approximately) were donated by 13 patients ( 5 females and 8 males) undergoing lobar resection for malignancy. The median age was 71 . Ethical approval was obtained from the North Bristol and United Bristol Healthcare Trusts.

\section{Immunohistochemistry for VEGF}

Normal, early ARDS and later ARDS lung tissue sections were examined ( $\mathrm{n}=8$ for each group). Normal lung tissue implied that there was no lung involvement in the cause of death. Paraffinised $4 \mu \mathrm{m}$ sections were de-waxed in serial xylene (BDH Laboratory Supplies, Poole, UK), dehydrated in absolute ethanol (BDH Laboratory Supplies, Poole, UK) and pressure cooked in $0.01 \mathrm{M}$ trisodium citrate (BDH Laboratory Supplies, Poole, UK) buffer ( $\mathrm{pH} \mathrm{6)}$ to facilitate antigen retrieval. Endogenous peroxidase was blocked with 3\% hydrogen peroxide (BDH Laboratory Supplies, Poole, UK) in methanol (BDH Laboratory Supplies, Poole, UK). Sections were incubated in 2.5\% horse blocking serum (Vectastain Universal Quick Kit, Vector Laboratories, Peterborough, UK) prior to Avidin D and Biotin blocking sera (Vector Laboratories, Peterborough, UK). A rabbit polyclonal antibody to VEGF Autogen Bioclear, UK Ltd, Wiltshire, UK) and isotypic rabbit IgG controls (Vector Laboratories, Peterborough, UK) were used. Isotypic control antibodies were used on normal, early ARDS and later ARDS tissues. The samples were then stained with pan-specific biotinylated antibody, streptavidin-peroxidase complex with diaminobenzidine substrate (Vectastain Universal Quick Kit, Vector Laboratories, Peterborough, UK), counterstained in haematoxylin (BDH Laboratory Supplies, Poole, UK).

Image capture and semi-quantitative densitometry were achieved using Histometrix version 6 software version 1.4 (Kinetic Imaging) linked to a JVC TK-C1360B camera with a resolution of 470 TV lines. Pixels representing immunopositivity were chosen and this threshold was memorised by the software. Anything within the selected pixel range was accounted for and expressed as a percentage of the 
pixels in the selected area. This gave a composite intensity score per unit area derived from the staining intensity value divided by the staining cross-sectional area assessed. Densitometry was performed on all slides from the same procedure assigning the same random coloration as unit of intensity on each slide. Five randomly chosen (computer generated) areas on each section for each patient were assessed giving twenty values. Densities on negative control sections were subtracted from positively stained section densities to control for differing background pixel intensities detected.

\section{Formalin-fixed paraffin embedded (FFPE) RNA extraction and measurement}

This method is a modified version of the Krafft technique[22]. Briefly, $8 \times 6 \mu \mathrm{m}$ sections were cut on a microtome from formalin-fixed paraffin-embedded (FFPE) blocks of archival normal, "early" (within 48 hours) and "later" ARDS (after day 7) lung tissue. Sections were dewaxed and washed in Histoclear II and absolute ethanol. Sections were then dried at $55^{\circ} \mathrm{C}$ for 3 minutes before being digested for 6 hours in digest buffer $(1 \mathrm{mg} / \mathrm{ml}$ proteinase K, $20 \mathrm{mM}$ Tris, $20 \mathrm{mM}$ EDTA buffer at pH 7.4, 1\% SDS) at the same temperature. After ice cooling, RNA was extracted using phenol:chloroform:isoamyl ethanol mixture before precipitation in sodium acetate, washing and pelleting.

\section{Animal model of lung injury}

Male C57BL/6 mice (18-20 g) were used in a LPS induced model of lung injury. The experiments were done in accordance with Home Office guidelines. Briefly mice were exposed to intranasal LPS (Sigma, Poole, UK; serotype 011:B4) dissolved in pyrogen-free saline. Animals were lightly anaesthetised by placing in a vapour-filled chamber with halothane (Merial Animal Health). While anaesthetised, intranasal inoculation of $50 \mu \mathrm{l}$ of $10 \mu \mathrm{g}$ LPS/mouse was performed. This procedure was repeated daily for 4 days. Control animals were treated with the same volume of pyrogen-free saline. Animals were sacrificed by halothane hyperanaesthesia and exsanguinated by cardiac puncture. The lungs were removed, inflated and snap frozen at day 2 and day 5 post initial LPS insult, 24 hours after last LPS dose. A minimum of $\mathrm{n}=4$ individual specimens was utilized in each experiment. Lung injury was confirmed by histological analysis and RNA extracted as previously described[23]. Quantitative realtime PCR was undertaken in the day 5 post LPS mice only.

\section{Isolation and purification of ATII cells}

ATII cells were purified according to the method of Witherden et al[24] as previously described. Sections were perfused with $0.9 \%$ saline, digested with $0.25 \%$ trypsin (Sigma, Poole, UK) and minced with newborn calf serum (NCS) (Invitrogen, Paisley). DNAse I was added to the suspension at $250 \mu \mathrm{g} / \mathrm{ml}$ in $7 \mathrm{ml}$ Hanks Balanced Salt
Solution (HBSS). The suspension was shaken before filtering through a $\sim 500 \mu \mathrm{m}$ filter and then $40 \mu \mathrm{m}$ mesh (Fahrenheit, Milton Keynes). ATII cells were purified by differential adhesion. The non-adherent cells were centrifuged at $300 \mathrm{~g}$ for 10 minutes at $4{ }^{\circ} \mathrm{C}$ and resuspended at $1 \times 10^{6} \mathrm{ATII}$ cells $/ \mathrm{ml}$ in complete media and put into 60 $\mathrm{mm}$ dishes (Greiner Cell Star, Stonehouse) pre-coated with Vitrogen-100 (Cohesion Technologies, Palo Alto, USA). The ATII cells were subsequently adhered at $37^{\circ} \mathrm{C}$ for 24 hours. The medium and any remaining contaminating cells were removed and fresh complete medium added. The cells were incubated for 16 hours, the medium removed and the cells washed with HBSS. Fresh complete medium was added and the cells incubated for a further 24 hours to establish confluent monolayers with ATII cell morphology confirmed as previously described[24]. ATII cell phenotype was confirmed by positive staining for alkaline phosphatase and mRNA transcripts for SP-C and aquaporin-3. Morphological characteristics were confirmed by electron microscopy. ATI cell phenotype was excluded by negative staining for aquaporin- 5 .

Purified cells were then either cultured with the proinflammatory agents LPS $(10 \mu \mathrm{g} / \mathrm{ml})$, TNF- $\alpha(10 \mathrm{ng} / \mathrm{ml})$, IL-1b (1 ng/ml) for 4 hours prior to RNA extraction and/ or sequential cell culture supernatant sampling or used in the proliferation assays described below. A minimum of 10 subject samples were used for each experiment. In vitro these cells rapidly differentiate and this precludes a prolonged culture timepoint.

\section{VEGF isoform-specific RT-PCR}

Human and murine RNA was extracted using TRIzol reagent. Reverse transcription (RT) was carried out using the Superscript II system (Invitrogen). Beta ${ }_{2}$-microglobulin $\left(B_{2} M\right)$ was used as a housekeeping gene. Amplifications were carried out in a $20 \mu \mathrm{l}$ reaction volume containing 13 $\mu \mathrm{l}$ RNase free water, $1.2 \mu \mathrm{l} 25 \mathrm{mM} \mathrm{MgCl}_{2}$ (final concentration $1.5 \mathrm{mM}$ ) (Abgene), $0.4 \mu \mathrm{l} 25 \mu \mathrm{M}$ dNTPs (Abgene), 1 $\mu \mathrm{l}$ of $20 \mu \mathrm{M}$ forward and reverse primers, $2 \mu \mathrm{l} 10 \times$ reaction buffer (Abgene) and $0.4 \mu \mathrm{l} 5 \mathrm{U} / \mu \mathrm{l}$ Taq DNA polymerase (Abgene). The following PCR conditions were used: denaturation at $94^{\circ} \mathrm{C}$ for 3 minutes, annealing at $72^{\circ} \mathrm{C}$ for 30 seconds then denaturation at $94^{\circ} \mathrm{C}$ for 30 seconds. The coding sequences for human VEGF (accession no. NM_000493, NM_001844, and NM_000088, respectively) and murine VEGF (MN_00441242 for mouse VEGF) were used to design primers using the online software, Primer3 (Whitehead Institute for Biomedical Research, Cambridge, MA). The primers span intronic junctions to avoid the amplification of genomic sequences. Primer sequences used were as in Table 1. Amplified products were visualized by gel electrophoresis using ethidium bromide (Sigma, Poole, UK) on a transilluminator (BioRad, Hertfordshire, UK) using semi-quantitative densitometric analysis (Biorad Geldoc software). 
Table I: Table of primer sequences for semi-quantitative RT-PCR for human VEGF and beta-microglobulin (B ${ }_{2}$ M)

\begin{tabular}{llc}
\hline RT-PCR Product & sense & antisense \\
\hline human VEGF $121,165,189$ & 5'-GAGATGAGCT TCCTACAGCAC-3' & 5'-TCACCGCCTCGGCTTGTCACAT-3' \\
\hline B $_{2} M$ & 5'-GCATCATGGAG GTTTGAAGATG-3 & 5'-TAAGTTGCCAG CCCTCCTAGAG-3' \\
\hline
\end{tabular}

Control reactions were run without the addition of reverse transcriptase. Previous experiments had determined the RT-PCR data would be in linear phase at a cycle number of 35 indicating the data were truly semi-quantitative. The inter-assay variability of densitometry measurements was $11.2 \%$.

\section{Quantitative real-time RT-PCR}

Quantitative real-time RT-PCR for VEGF isoforms was performed in a $25 \mu \mathrm{l}$ reaction volume containing $12.5 \mu \mathrm{l}$ of the SYBR Green PCR master mix (Sigma, Poole, UK), $5 \mu \mathrm{l}$ of the RT reaction mixture, and $300 \mathrm{nM}$ each primer using the Smart Cycler II System (Cepheid, Sunnyvale, CA). A standard curve was generated for each test mRNA using 8 serial dilutions from neat RNA to 1:200,000. The amplification program consisted of initial denaturation at $95^{\circ} \mathrm{C}$ for 2 minutes followed by 40 cycles of $95^{\circ} \mathrm{C}$ for $15 \mathrm{sec}-$ onds, annealing at $58^{\circ} \mathrm{C}$ for 30 seconds, and extension at $72^{\circ} \mathrm{C}$ for 15 seconds. Primer sequences were as in Table 2. Commercially available GAPDH primers were used http:/ /www.primerdesign.co.uk and used as a reference for normalization in all RT-polymerase chain reactions (RTPCRs).

\section{VEGF ELISA}

Cell culture supernatants were assayed for VEGF (VEGF $_{121}$, VEGF $_{165}$ only) using a commercial ELISA kit (R\&D Systems). In brief, a specific monoclonal antibody was coated onto a microplate. Standards and samples were added and a polyclonal detection antibody added. The resultant colour developed in proportion to the amount of growth factor present and was read spectrophotometrically. The detection limit was $3 \mathrm{pg} / \mathrm{ml}$.

\section{Cell Proliferation Assay ( ${ }^{3} \mathrm{H}$-thymidine incorporation)}

ATII cells were seeded in 24-well plates (Greiner bio-one Ltd, Stonehouse, UK) in complete medium $(10 \% \mathrm{NCS} /$ DCCM/1\% penicillin/streptomycin/amphotericin B) (Sigma, Poole, UK) at 100,000 cells per well. For 48 hours the cells were incubated in $5 \mathrm{ng} / \mathrm{ml} \mathrm{VEGF}_{165} \pm 10 \mathrm{ng} / \mathrm{ml}$ $s f l t, 10 \mathrm{ng} / \mathrm{ml} \mathrm{KGF} \mathrm{(as} \mathrm{a} \mathrm{positive} \mathrm{control)} \mathrm{and} 10 \mathrm{ng} / \mathrm{ml} \mathrm{sflt}$ (as a specific VEGF inhibitor) alone. The concentrations of KGF and sflt correspond to previously published concentrations in primary cell studies. $5 \mathrm{ng} / \mathrm{ml} \mathrm{VEGF}_{165}$ approximates to epithelial lining fluid concentrations of VEGF in normal subjects and also following recovery from ARDS $[4,8]$. The cells were then washed with HBSS (Sigma, Poole, UK) and incubated in complete medium. Recombinant proteins and $37 \mathrm{kBq}$ methyl-[3 $\left.{ }^{3} \mathrm{H}\right]$ thymidine (Amersham Biosciences) were added to each well. At 48 hours incubation at $37^{\circ} \mathrm{C}$, the cells were washed with trichloracetic acid 5\% in PBS and then solubilized by adding $0.5 \mathrm{ml}$ of $0.3 \mathrm{M} \mathrm{NaOH}$ (Sigma, Poole, UK). Cell lysates were subsequently pipetted into scintillation vials (Fisher Scientific UK Ltd, Loughborough, Leicestershire, UK) containing $2 \mathrm{mls}$ of scintillation liquid (Amersham Biosciences) and counted by a $\beta$-counter; Beckmann Instruments (Beckman Coulter Ltd, High Wycombe, Buckinghamshire, UK).

\section{Cell count}

ATII were seeded in 24-well plates (Greiner Bio-one Ltd, Stonehouse, UK) in complete medium, at 100,000 cells per well. After 48 hours, cells were washed with HBSSS and the protein of interest added. After 48 hours incubation, cells were washed with PBS and incubated with 100 $\mu \mathrm{l}$ of Trypsin-EDTA (Sigma, Poole, UK). When the cells

Table 2: Table of primer sequences for quantitative real time PCR (QPCR) for human and murine VEGF

\begin{tabular}{lll}
\hline QPCR Product & sense & antisense \\
\hline human VEGF 165 & 5'-ATCTTCAAGCCATCCTGTGTGC-3' & 5'-CAAGGCCCACAGGGATTTTC-3' \\
\hline human VEGF 189 & 5'-ATCTTCAAGCCATCCTGTGTGC-3' & 5'-CACAGGGAACGCTCCAGGAC-3' \\
\hline murine VEGF 120 & 5'-AACGATGAAGCCCTGGAGTG-3' & 5'-TGAGAGGTCTGGTTCCCGA-3' \\
\hline murine VEGF 164 & 5'-AACGATGAAGCCCTGGAGTG-3' & 5'-GACAAACAAATGCTTTCTCCG-3' \\
\hline murine VEGF 188 & 5'-AACGATGAAGCCCTGGAGTG-3' & 5'-AACAAGGCTCACAGTGAACG-3'
\end{tabular}


were unattached, $100 \mu \mathrm{l}$ of culture medium containing $10 \%$ FBS was added. Cells were then counted under the microscope using a haemocytometer.

\section{Statistics}

Data were analyzed by ANOVA with Bonferroni post hoc multiple comparison correction using GraphPad Prism version 4.0 software. A p value of $<0.05$ was considered significant.

\section{Results}

Human VEGF lung expression and quantification in normal, early and late ARDS

Human VEGF expression was noted on alveolar epithelium and macrophages with weaker endothelial expression in all human tissue sections. VEGF expression was significantly increased in late ARDS compared to both normal subjects and early ARDS ( $\mathrm{p}<0.001)$ (Figure 1$)$. This represented all VEGF isoforms both soluble and membrane-bound.

\section{Human VEGF isoform RT-PCR in normal, early and late ARDS}

In order to determine the individual VEGF isoforms, RTPCR was initially used. A representative RT-PCR gel from the human FFPE tissue is shown in Figure 2a. When individual isoforms were compared between groups, a significant increase in all three isoforms was detected in later versus early ARDS $(\mathrm{p}<0.05)$ as seen in Figure $2 \mathrm{~b}-\mathrm{d}$. However, when considering individual relative isoform production in disease there was a significant decrease in the relative ratio of soluble to cell-associated isoforms in early ARDS ( $p<0.05)$ as seen in Figure 2e (comparing combined densitometry data).

\section{Murine VEGF mRNA expression}

The human samples used were of archival post-mortem origin and hence potentially subject to post mortem degradation although a recent study suggests that this is minimal[25]. In order to support these human findings, we repeated the mRNA analysis in samples extracted from snap frozen murine whole lung injury samples. We demonstrated a significant fold increase in all isoforms ( $\mathrm{p}<$ 0.05 ) (Figure 3). Analysis of absolute values showed a significantly greater amount of $\mathrm{VEGF}_{188}$ than $\mathrm{VEGF}_{164}$ and $\operatorname{VEGF}_{120}(\mathrm{p}<0.05)$.

\section{ATII VEGF mRNA isoform expression (RT-PCR)}

The main source of VEGF on the basis of our immunocytochemistry results were ATII cells so we isolated these for further investigation. We found that ATII cells constitutively express mRNA for all the three main VEGF isoforms: $\mathrm{VEGF}_{121}, \mathrm{VEGF}_{165}$ and $\mathrm{VEGF}_{189}$ (Figure 4a). All isoforms were significantly increased in comparison to control following treatment with $10 \mathrm{ng} / \mathrm{ml} \mathrm{VEGF}_{165}(\mathrm{p}<0.05$ for VEGF $_{165}, \mathrm{p}<0.01$ for other isoforms) and $10 \mu \mathrm{g} / \mathrm{ml}$ LPS
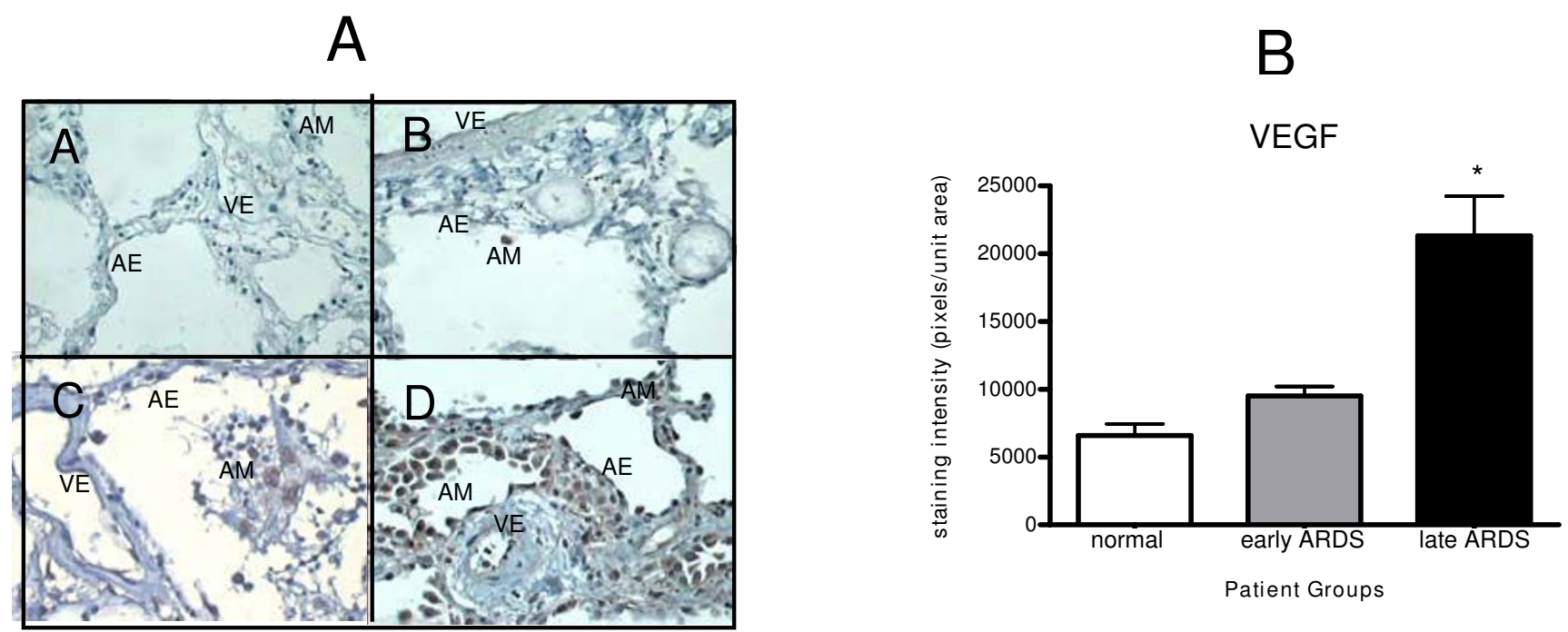

Figure I

A) Immunocytochemistry of human whole lung tissue ( $\times 40)$ showing (A) isotypic control (from later ARDS), (B) normal controls, (C) early ARDS, (D) later ARDS (magnification $\times$ 40). Immunostaining shows positive VEGF expression in alveolar epithelium (AE), alveolar macrophages (AM) and (to a lesser extent) vascular endothelium (VE). Significant increase in staining noted in ARDS, especially later ARDS. Staining was assessed semiquantitatively using Histometrix software analysis. B) Histometric analysis of human VEGF in healthy human lung, early and later ARDS. $* P<0.00 \mathrm{I}$ in later ARDS versus early ARDS and normal, (ANOVA with post-hoc Bonferroni). Data are normal and plotted as mean and standard error. 
A

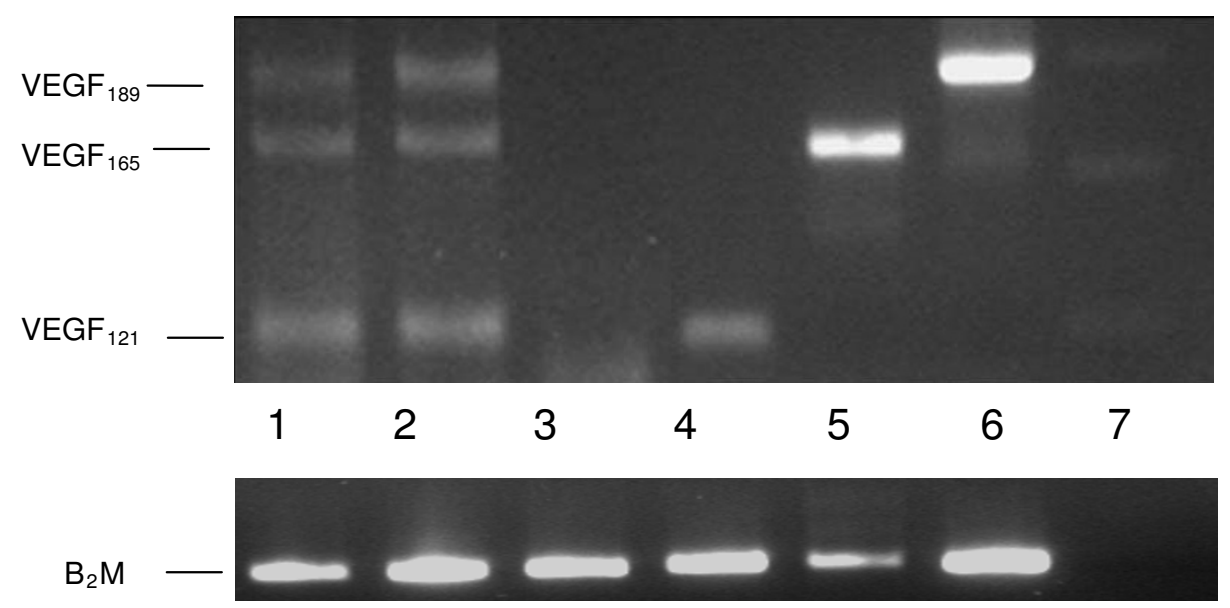

B
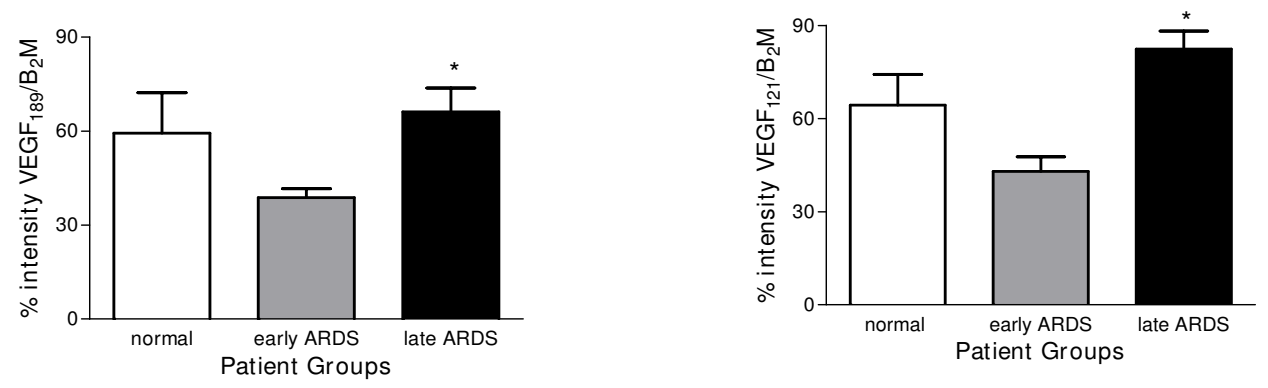

C

$E$
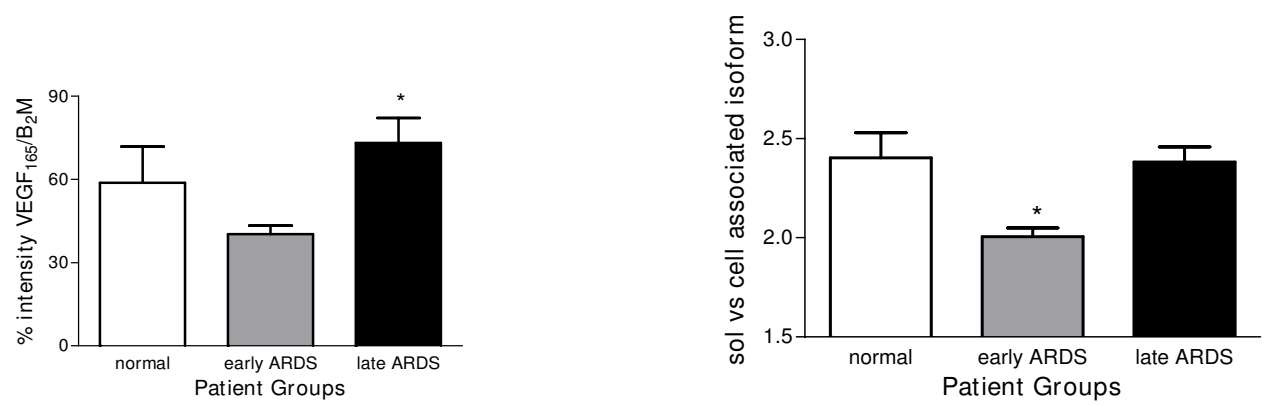

Figure 2

A): Representative RT-PCR gel for human VEGF isoforms in normal, early and later ARDS, lanes as follows: (I) early ARDS, (2) later ARDS, (3) negative control, $(4,5,6)$ sequenced positive controls $\left(V^{2} G_{121}\right.$, VEGF VE5 $_{165}$ and VEGF 189 respectively), (7) 100 kb ladder (bottom marker denotes $100 \mathrm{bp}$, top marker $300 \mathrm{bp}$ ). B-E): Semiquantitative densitometry of (B) VEGF 189 , (C) VEGF $\mathrm{VEF}_{165}$, (D) VEGF $\mathrm{VEF}_{121}$ relative to $\beta$-microglobulin $\left(\mathrm{B}_{2} \mathrm{M}\right)$ in normal, early and later ARDS (*p $<0.05$ late versus early ARDS), $(E)$ ratio of soluble $\left(\mathrm{VEGF}_{121}, \mathrm{VEGF}_{165}\right)$ to cell-associated $\left(\mathrm{VEGF}_{189}\right)$ isoforms (*p < 0.05 early versus normal and later ARDS). Data are plotted as means with bars denoting standard errors (ANOVA with posthoc Bonferroni) for B-E). 

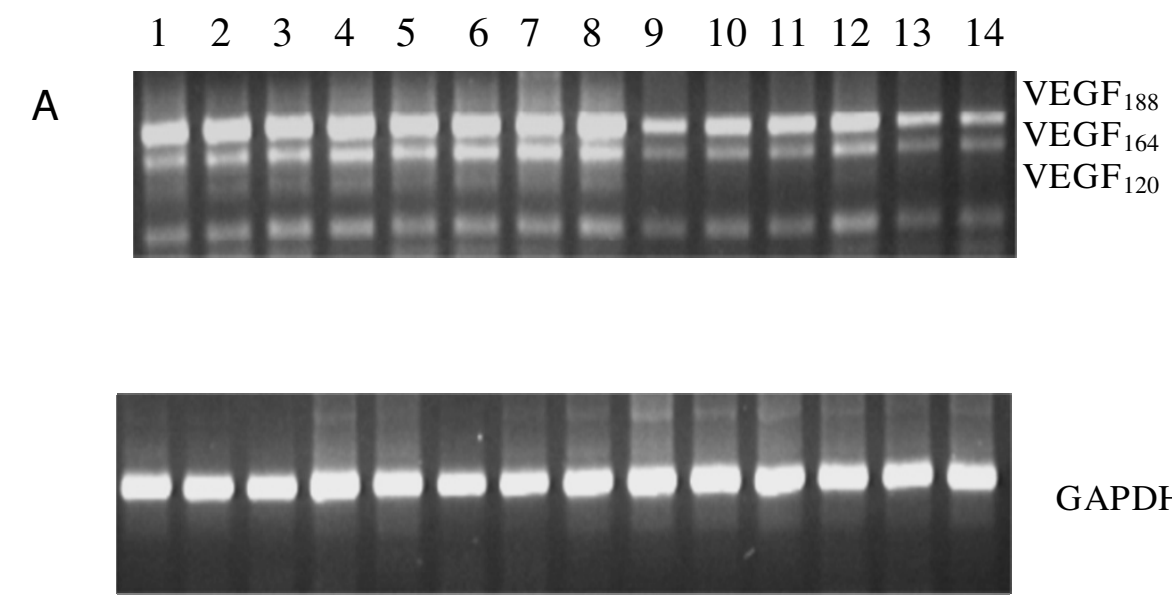

\section{GAPDH}

Fold

change in

VEGF $_{120}$

mRNA
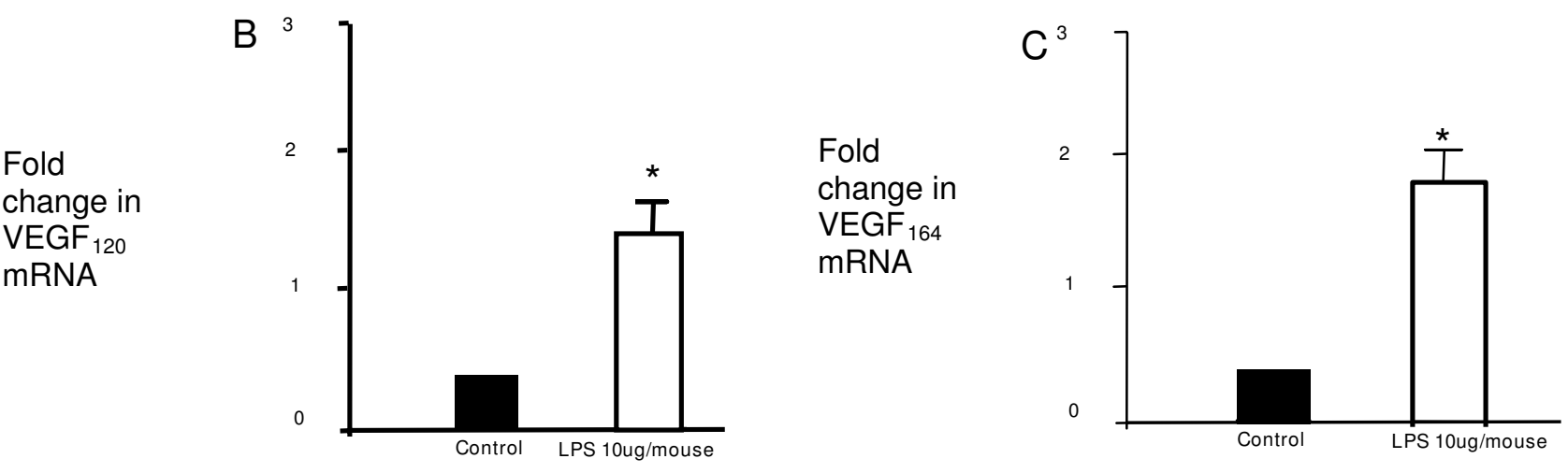

Fold

change in

VEGF $_{188}$

mRNA

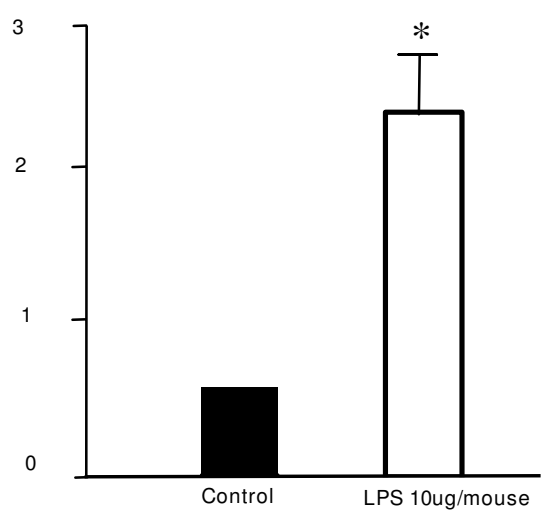

\section{Figure 3}

4 samples were examined for each treatment group. A) Representative RT-PCR gel of VEGF isoforms in control and injured murine lung. Lanes are as follows: (I-8) injured murine lung at day 5 (24 hours post last LPS dose) (9-I2) injured murine lung at day 2 (24 hours post last LPS dose), (I3-14) control murine lung. B-D): Further real-time PCR analysis was

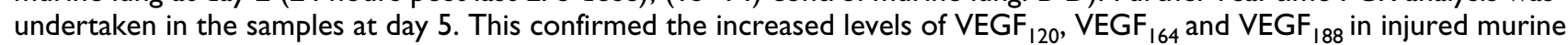
lung $\left(*_{p}<0.05\right.$ fold change compared to control). 
A

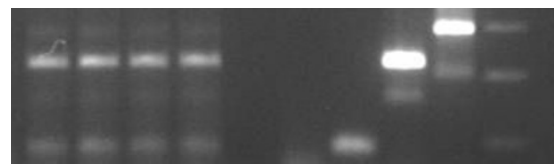

—VEGF 189

$\leftarrow$ VEGF 165

ŁVEGF 121

$\begin{array}{llllllllll}1 & 2 & 3 & 4 & 5 & 6 & 7 & 8 & 9 & 10\end{array}$

B

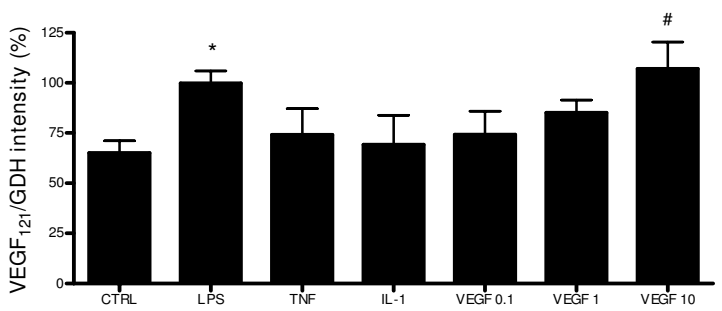

C

$\mathrm{F}$
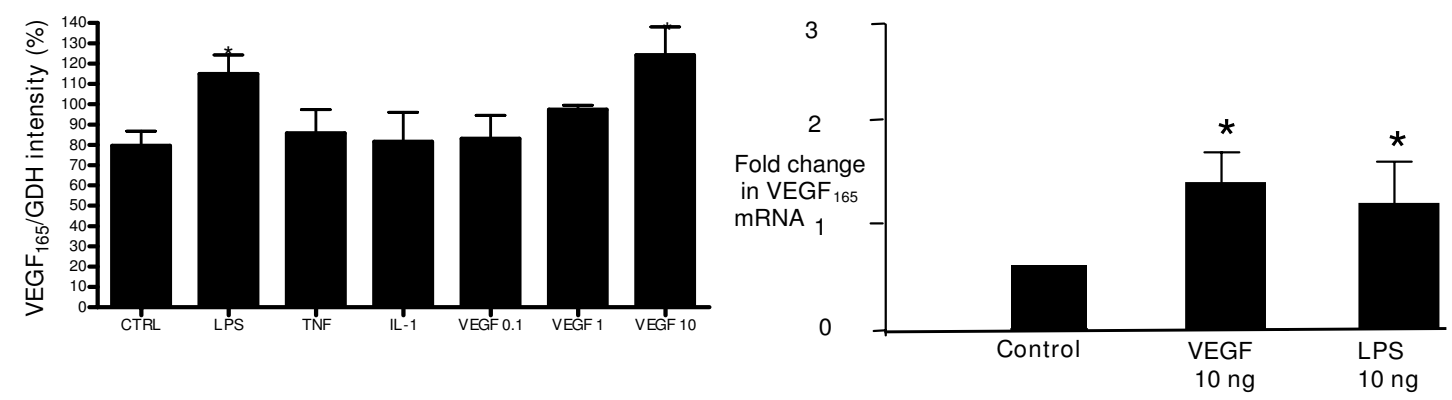

$\mathrm{D}$

$\mathrm{F}$
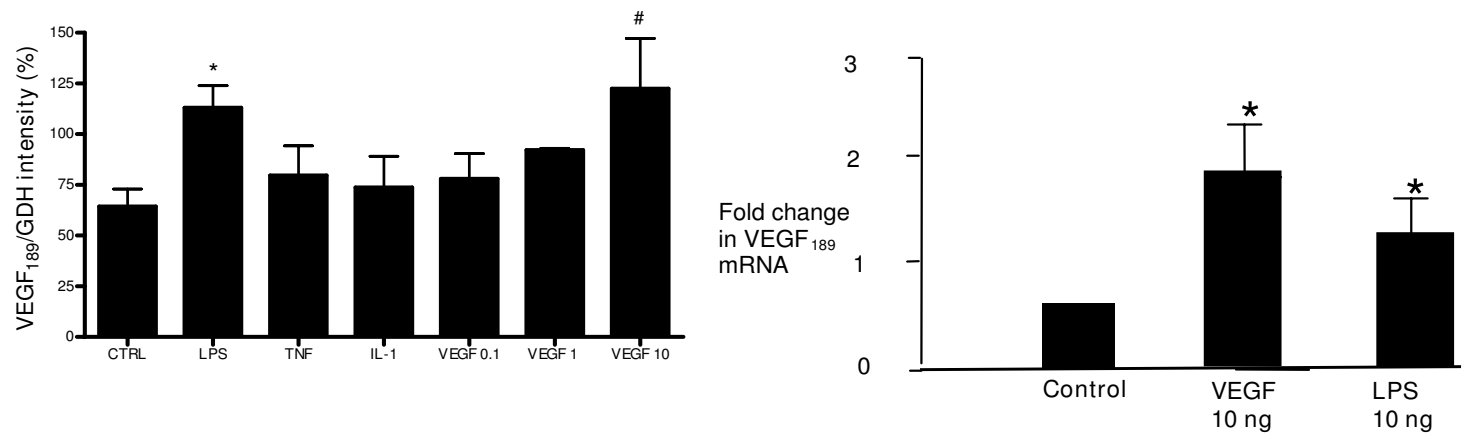

Figure 4

A) Representative RT-PCR gel of VEGF isoforms in ATII cells. Lanes are as follows: (I-4) human ATIl cell samples, (5) blank, (6) negative control, (7-9) sequenced positive controls for $\mathrm{VEGF}_{121}, \mathrm{VEGF}_{165}$ and $\mathrm{VEGF}_{189}$ respectively, (I0) $100 \mathrm{~kb}$ ladder (bottom marker denotes 100 bp, top marker denotes 300 bp). B-D): Semiquantitative densitometry data $(n=8$, in triplicate) showing VEGF $121, V$ EGF $_{165}$ and VEGF 189 in response to LPS $(10 \mu \mathrm{g} / \mathrm{ml})$, TNF- $\alpha(10 \mathrm{ng} / \mathrm{ml}), \mathrm{IL}-\mathrm{I} \beta, \mathrm{VEGF}_{165}(0.1, \mathrm{I}, 10 \mathrm{ng} / \mathrm{ml})$ at 4 hours. Data are plotted as mean with bars denoting standard error. $* \mathrm{P}<0.05$ (ANOVA post hoc Bonferroni) $10 \mu \mathrm{g} / \mathrm{ml}$ LPS versus control (all isoforms) and $10 \mathrm{ng} / \mathrm{ml} \mathrm{VEGF}_{165}$ versus control $\left(\mathrm{VEGF}_{165}\right.$ only). $\# \mathrm{P}<0.01$ (ANOVA, post hoc Bonferroni) 10 $\mathrm{ng} / \mathrm{ml}$ VEGF versus control $\left(\mathrm{VEGF}_{121}\right.$ and $\left.\mathrm{VEGF}_{189}\right)$. E-F): Further real-time PCR analysis confirmed the effect of LPS and VEGF on $\mathrm{VEGF}_{165}$ and $\mathrm{VEGF}_{189}(* \mathrm{p}<0.05$ fold change compared to control). 
( $\mathrm{p}<0.05$ ) at 4 hours (Fig 4b-d). Other pro-inflammatory stimuli (TNF, IL-1) and lower concentrations of VEGF 165 did not alter relative VEGF isoform expression. These results were confirmed by Q-PCR showing a doubling of $\mathrm{VEGF}_{189}$ and $\mathrm{VEGF}_{165}$ compared to control $(\mathrm{p}<0.05)$ in response to LPS $10 \mu \mathrm{g} / \mathrm{ml}$ and VEGF $10 \mathrm{ng} / \mathrm{ml}$ (Figure 4ef).

\section{ATII VEGF protein levels and response to LPS}

Having determined the production of VEGF isoforms at the mRNA level we went on to assess the release of the soluble isoforms $\left(\mathrm{VEGF}_{121}, \mathrm{VEGF}_{165}\right)$ by the cultured cells. ATII cells express significant amounts of $\mathrm{VEGF}_{121}$ and VEGF $_{165}$ constitutively (Figure 5). These levels significantly increased with time in human ATII supernatant (p $<0.01$ vs control at 24 hours). At 24 hours, LPS (100 ng/ $\mathrm{ml})$ further stimulated VEGF production $(\mathrm{p}<0.05)$.

\section{ATII proliferation}

Having determined the production of VEGF by the ATII cell population, we explored the potential effect of VEGF $_{165}$ on these cells. An increase in human ATII cell proliferation as assessed by ${ }^{3} \mathrm{H}$-thymidine was detected with $5 \mathrm{ng} / \mathrm{ml} \mathrm{VEGF}_{165}(\mathrm{p}<0.001)$, comparable to levels detected previously in bronchoalveolar lavage fluid[8]). Furthermore, with the addition of a natural VEGF inhibitor, soluble VEGFR1 (sflt), there was a significant reduction in proliferation compared to serum control ( $\mathrm{p}<$ 0.05 ) suggesting an autocrine effect (Figure 6). The addition of sflt alone and in combination with VEGF $_{165}$ showed no significant difference in cell number compared to serum control $(\mathrm{p}>0.05)$ but did significantly inhibit VEGF $_{165}$-induced increase in cell number $(\mathrm{p}<0.001 \mathrm{com}$ pared to $5 \mathrm{ng} / \mathrm{ml} \mathrm{VEGF}_{165}$ ). This suggested that $\mathrm{VEGF}_{165}$ was inducing proliferation rather than survival alone.

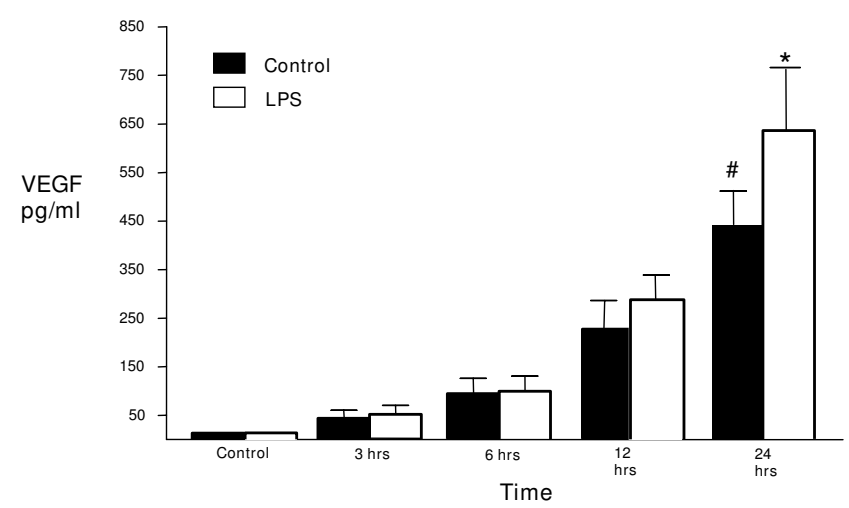

Figure 5

ATII cell supernatant levels of VEGF protein significantly increases with time in unstimulated cells, unstimulated cell supernatants control v 24 hrs, filled bars, $(\# p<0.01)$ with a significant increase in response to LPS $100 \mathrm{ng} / \mathrm{ml}$ at 24 hours, unfilled bars, (*p < 0.05), ANOVA with post hoc Bonferroni.

\section{Discussion}

Previous observational data by ourselves and others have demonstrated plasma VEGF levels rise and intrapulmonary levels fall in the early stages of lung injury with normalization of both during recovery $[7,8]$. Similarly, reduced levels of VEGF have been described in normal smokers and patients with idiopathic pulmonary fibrosis (IPF); other conditions in which damage to the alveolar epithelium may be present[26].

Potential explanations for the apparent reduction in intrapulmonary VEGF levels in early ARDS are manifold and not mutually exclusive. They include increased membrane-bound rather than soluble isoforms, changes in isoform expression and damage to the alveolar-capillary membrane with consequent leakage of intrapulmonary VEGF into the vascular bed [27-30].

We therefore assessed expression of VEGF and its specific isoforms by immunohistochemistry and isoform-specific RT-PCR (as isoform-specific antibodies are not available) in archival normal and ARDS lung tissue. We demonstrated a significant up-regulation of VEGF in later ARDS tissue compared to normal subjects. However in early ARDS, in contrast to our epithelial lining fluid (ELF) findings we did not detect a reduction in total VEGF expression[8]. One other group has also explored this area, but using different timepoint characteristics, whole tissue homogenates including inflammatory cells and did not assess differential isoform expression[11]. In both these studies ELISA methodology was used which detects only the soluble isoforms, $\mathrm{VEGF}_{121}$ and $\mathrm{VEGF}_{165}[8]$.

In order to consider changes in isoform expression as a possible explanation for these discrepancies, we assessed mRNA as there are no isoform-specific antibodies currently. No significant reduction in VEGF isoform expression occurred in early ARDS in comparison to normal subjects although a trend was suggested. However, significant changes were detected between early and later ARDS in all isoforms and there was a significant decrease in the relative ratio of soluble to cell-associated isoforms in early ARDS compared to later ARDS and normal subjects. In the context of our previous ELF findings, this data is supportive of the suggestion that isoform switching is a critical regulatory mechanism for VEGF bioactivity in that isoform-specificity may be important in ligand-VEGF receptor interactions[31]. Furthermore, there is more potential for soluble VEGF to have extrapulmonary effects which is extremely relevant since the most common cause of death in ARDS is multi-organ system failure[32,33].

Obtaining ARDS lung tissue is limited by the lack of surgical biopsies of this disease in our clinical practice and theoretically necropsy lung tissue might introduce selec- 


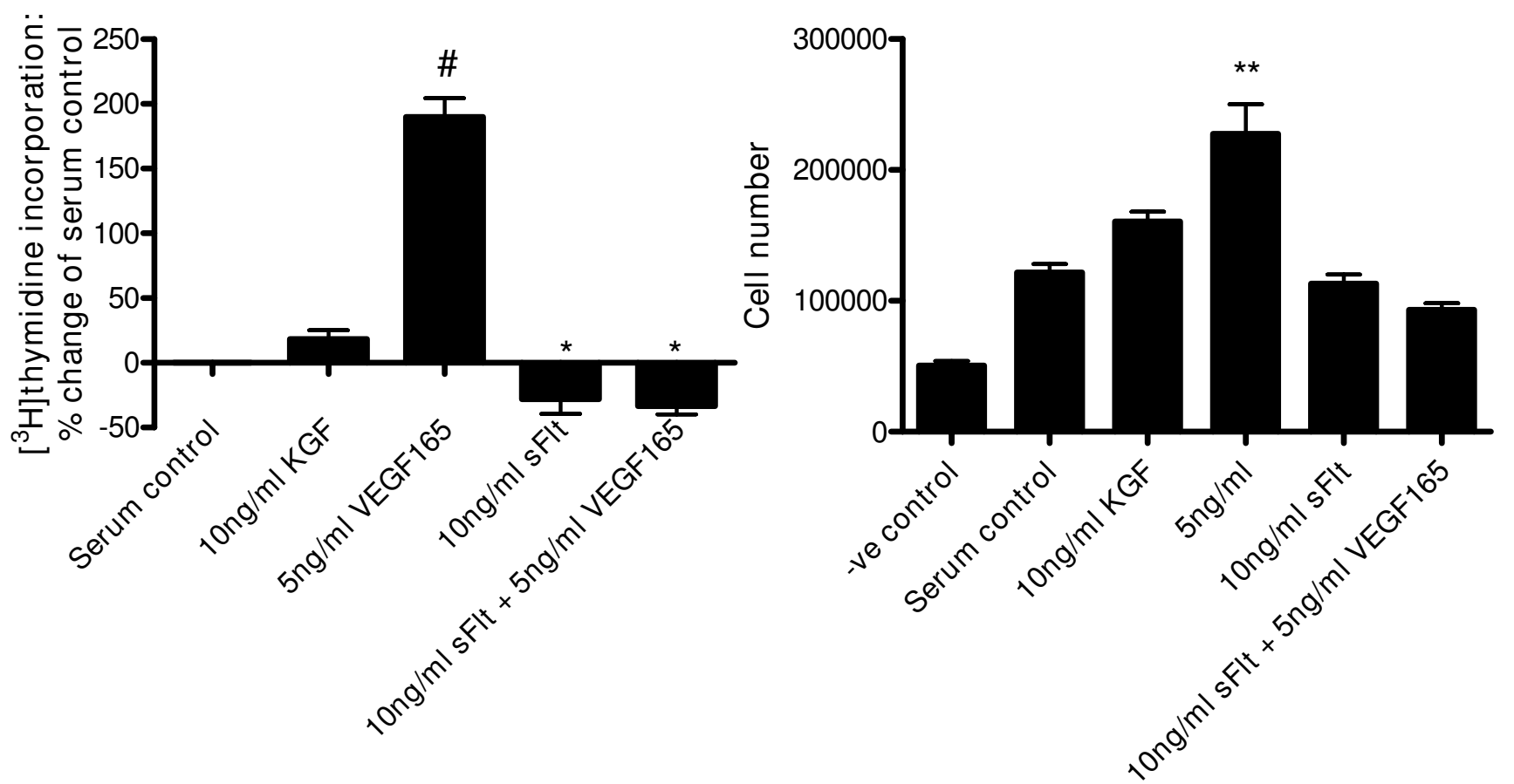

Figure 6

Bar graphs depicting ${ }^{3} \mathrm{H}$-thymidine incorporation into ATII cells (A) and cell number (B) following treatment for 48 hours with VEGF $5 \mathrm{ng} / \mathrm{ml}$, sflt $10 \mathrm{ng} / \mathrm{ml}$ and combination confirming a significant proliferation with VEGF $5 \mathbf{n g} / \mathbf{m l}$ (\#p < $\mathbf{0 . 0 0 I}$ vs serum control). The presence of sflt not only inhibited the proliferative effect of VEGF but also reduced proliferation below that of serum controls $\left(*_{p}<0.05\right)$, suggesting an autocrine effect. Cell number also increased significantly with $5 \mathrm{ng} / \mathrm{ml} \mathrm{VEGF}_{165}(* * \mathrm{p}<0.0 \mathrm{I})$ compared to serum control. The addition of sflt alone and in combination with VEGF $_{165}$ showed no significant difference compared to serum control $(p>0.05)$ but did significantly inhibit VEGF 165 -induced proliferation ( $p<0.001$ compared to $\left.5 \mathrm{ng} / \mathrm{ml} \mathrm{VEGF}_{165}\right)$.

tion bias for a more severe spectrum of ARDS, as intrapulmonary VEGF levels are known to be lower in nonsurvivors with ARDS[8]. There was no evidence of any significant lung disease in the normal necropsy lung tissue, but it is conceivable that the extra-pulmonary disease process contributing to death might have affected VEGF levels although recent data suggests this is not the case[25]. In order to investigate this possibility we repeated this analysis in snap frozen lung tissue from our multiple dose LPS-induced lung injury model at day 5 post initial injury, reflecting early ARDS [23]. These data supported the human post mortem findings of an increase in cell-associated VEGF in an ARDS situation.

Previous in vitro studies had confirmed VEGF is abundant in lung and suggested the alveolar epithelium as a key source $[5,6,34]$. Several lines of in vitro evidence have pointed to a possible role for VEGF in lung repair and recovery following injury[19,29,35,36]. In one LPSinduced murine model of lung injury, intrapulmonary levels of VEGF increased following injury for 96 hours, mirroring the increase in bronchoalveolar lavage fluid protein and neutrophils with significant VEGF localization to lung epithelium but increases mainly in inflamma- tory cells [37]. However, previous experiments performed in our laboratory have confirmed $\mathrm{pg} / \mathrm{ml}$ levels of expression of VEGF in cultured alveolar macrophage supernatants from patients with ARDS and "at risk" of ARDS suggesting that they are unlikely to be the main cellular source of VEGF, although they may contribute [8]. In both newborn and adult rabbit, hyperoxic lung injury resulted in a relative reduction in $\mathrm{VEGF}_{189}$ and parallel increase in $\mathrm{VEGF}_{121}$ and $\mathrm{VEGF}_{165}$ mRNA expression with normalization to control values during recovery[38]. Therefore, we went on to investigate the role of human ATII cells as both a source and potential target for VEGF bioactivity.

We initially established at the mRNA level that ATII cells express the major VEGF isoforms $\left(\mathrm{VEGF}_{121,165}\right)$ (both soluble) and $\mathrm{VEGF}_{189}$ (membrane-associated). The specific functions of these isoforms have not been clearly identified in humans although genetically modified mouse models suggest they may be significant. Ideally, we would have isolated ATII cells from ARDS lung biopsies and undertaken mRNA analysis but this was not possible as described above. We have also shown that VEGF 165 is differentially upregulated by various exogenous compounds, in particular LPS. 
We demonstrated for the first time that primary human ATII cells constitutively produce soluble VEGF $\left(\right.$ VEGF $\left._{121,165}\right)$ isoforms in a dose-dependent manner that increased in response to LPS $(p<0.05)$. This is in agreement with other studies showing high ELF levels in normal human subjects[4]. The increase in constitutional production in time would suggest active secretion. The relationship of these findings at the protein level to those at the mRNA level is not clear-cut. The ELISA used does not differentiate between $\mathrm{VEGF}_{121}$ and $\mathrm{VEGF}_{165}$ and only detects the unbound free protein. Cell-associated VEGF is not detected and may be considerable.

The high intrapulmonary levels of VEGF and its changes in ARDS led us to hypothesise that VEGF may be an epithelial mitogen or survival factor. This has particular relevance in repair following injury as occurs in ARDS when the alveolar epithelial surface must be regenerated to clear fluid and restore the normal ATI cells and gas exchange[39]. The evidence for VEGF as an epithelial mitogen conflicts. Proliferation in human fetal explants[18] and acid-injured A549 cells[19,40] and surfactant production by murine ATII cells[36] have been described, but these data were not supported when rat ATII cells were used[20]. In the current study, we have shown for the first time that VEGF at $5 \mathrm{ng} / \mathrm{ml}$ (akin to normal human ELF VEGF levels), induces significant proliferation of these cells which is inhibited by the specific inhibitor $s f l t$. Furthermore, the reduction in proliferation by the addition of $s$ flt suggests a potential autocrine effect of this protein.

We have only explored the effects of $\mathrm{VEGF}_{165}$ in this study and other isoforms may also be relevant. In addition, sample numbers are limited and subject to biological heterogeneity inherent in primary cell studies and our preliminary findings need to be expanded upon and analysed individually in greater depth using techniques such as laser capture microdissection for single cell PCR analysis. VEGF $_{189}$ can be cleaved in into smaller units. Therefore, repeating these experiments with a cleavage inhibitor should be considered in the future. The relevance of this is that the concept of soluble versus cell-associated isoforms has not yet been fully resolved and proteolytic cleavage may alter isoform ratios in ways not detected in this study.

In conclusion, we present evidence that changes in VEGF isoforms occur between early and late ARDS. These data are supported by both murine model and isolated human ATII cell data. We have demonstrated ATII cells to be a source of VEGF isoforms upregulated by lipopolysaccharide, often implicated in the ARDS process. Finally we show evidence that $\mathrm{VEGF}_{165}$ is an ATII cell mitogen, inducing proliferation which was inhibited by soluble VEGFR1. These data suggest a key role for VEGF bioactivity in lung injury and ARDS.

\section{Ethics approval}

The protocol was approved by the North Bristol NHS Trust Local Research Ethics Committee.

\section{Competing interests}

The authors declare that they have no competing interests.

\section{Authors' contributions}

ARLM carried out the immunohistochemistry, FFPE RNA extraction, ATII cell isolation and culture, ELISA, semiquantitative RT-PCR, statistical analysis, drafted the manuscript and contributed to its design and conception. SKD carried out the proliferation studies and drafting of part of the manuscript. SIHG designed and generated the murine model and performed the murine RT-PCR. KMU and LA contributed to the ATII cell isolation and culture. KMG and BZ performed the real time PCR and contributed to drafting of part of the manuscript. TDT contributed to the ATII cell culture and drafting of part of the manuscript. NBN contributed to the immunohistochemistry and drafting of part of the manuscript. ABM conceived of the study, contributed to its design and drafted the manuscript. All authors read and approved the final manuscript.

\section{Acknowledgements}

We would like to thank the following for technical advice: Mr Haydn Kendall (immunohistochemistry), Ms Katy Chalmers (Histometrix software), Ms Rachel Perrin (VEGF isoform RT-PCR). We would also like to thank $\mathrm{Dr}$ Dave Bates for donation of positive control $\mathrm{VEGF}_{|2|}$ and $\mathrm{VEGF}_{165}$ isoform cDNA.

\section{References}

I. Ware LB, Matthay MA: The acute respiratory distress syndrome. N Engl J Med 2000, 342( I 8): | 334-I349.

2. Carmeliet P, Ferreira V, Breier G, Pollefeyt S, Kieckens L, Gertsenstein M, Fahrig M, Vandenhoeck A, Harpal K, Eberhardt C, Declercq C, Pawling J, Moons L, Collen D, Risau W, Nagy A: Abnormal blood vessel development and lethality in embryos lacking a single VEGF allele. Nature 1996, 380(6573):435-439.

3. Ferrara N, Gerber HP, LeCouter J: The biology of VEGF and its receptors. Nat Med 2003, 9:669-676.

4. Kaner RJ, Crystal RG: Compartmentalization of vascular endothelial growth factor to the epithelial surface of the human lung. Mol Med 200I, 7(4):240-246.

5. Koyama S, Sato E, Tsukadaira A, Haniuda M, Numanami H, Kurai M, Nagai S, Izumi T: Vascular endothelial growth factor mRNA and protein expression in airway epithelial cell lines in vitro. Eur Respir J 2002, 20(6): | 449- | 456.

6. Boussat S, Eddahibi S, Coste A, Fataccioli V, Gouge M, Housset B, Adnot S, Maitre $B$ : Expression and regulation of vascular endothelial growth factor in human pulmonary epithelial cells. Am J Physiol Lung Cell Mol Physiol 2000, 279(2):L37I-L378.

7. Thickett DR, Armstrong L, Christie SJ, Millar AB: Vascular endothelial growth factor may contribute to increased vascular permeability in acute respiratory distress syndrome. Am J Respir Crit Care Med 200 I, I 64(9): I60I-I605.

8. Thickett DR, Armstrong L, Millar AB: A role for vascular endothelial growth factor in acute and resolving lung injury. $A m \mathrm{~J}$ Respir Crit Care Med 2002, I 66( I 0): I 332-I337.

9. Maitre B, Boussat S, Jean D, Gouge M, Brochard L, Housset B, Adnot $S$, Delclaux C: Vascular endothelial growth factor synthesis in the acute phase of experimental and clinical lung injury. Eur Respir J 200I, I 8(I): 100-106. 
10. Hanaoka M, Droma Y, Naramoto A, Honda T, Kobayashi T, Kubo K: Vascular endothelial growth factor in patients with high-altitude pulmonary edema. J Appl Physiol 2003, 94: I836-1840.

II. Abadie Y, Bregeon F, Papazian L, Lange F, Chailley-Heu B, Thomas P, Duvaldestin P, Adnot S, Maitre B, Delclaux C: Decreased VEGF concentration in lung tissue and vascular injury during ARDS. Eur Respir J 2005, 25(I): I39-| 46.

12. Tischer E, Mitchell R, Hartman T, Silva M, Gospodarowicz D, Fiddes JC, Abraham JA: The human gene for vascular endothelial growth factor. Multiple protein forms are encoded through alternative exon splicing. J Biol Chem I991, 266( I 8): I 1947-II954.

13. Robinson CJ, Stringer SE: The splice variants of vascular endothelial growth factor (VEGF) and their receptors. J Cell Sci 200I, I I 4(Pt 5):853-865.

14. Houck KA, Ferrara N, Winer J, Cachianes G, Li B, Leung DW: The vascular endothelial growth factor family: identification of a fourth molecular species and characterization of alternative splicing of RNA. Mol Endocrinol 1991, 5(12):|806-1814.

15. Ferrara N: Vascular endothelial growth factor: basic science and clinical progress. Endocr Rev 2004, 25(4):58I-6II.

16. Fehrenbach $\mathrm{H}$ : Alveolar epithelial type II cell: defender of the alveolus revisited. Respir Res 200I, 2(I):33-46.

17. Maniscalco WM, Watkins RH, Finkelstein JN, Campbell MH: Vascular endothelial growth factor mRNA increases in alveolar epithelial cells during recovery from oxygen injury. $A m \mathrm{~J}$ Respir Cell Mol Biol 1995, I 3(4):377-386.

18. Brown KR, England KM, Goss KL, Snyder JM, Acarregui MJ: VEGF induces airway epithelial cell proliferation in human fetal lung in vitro. Am J Physiol Lung Cell Mol Physiol 200I, $28 I(4): L I 00 I-L I O I O$.

19. Roberts JR, Perkins GD, Fujisawa T, Pettigrew KA, Gao F, Ahmed A, Thickett DR: Vascular endothelial growth factor promotes physical wound repair and is anti-apoptotic in primary distal lung epithelial and A549 cells. Crit Care Med 2007, 35(9):2164-2170.

20. Raoul W, Chailley-Heu B, Barlier-Mur AM, Delacourt C, Maitre B, Bourbon JR: Effects of vascular endothelial growth factor (VEGF) on isolated fetal alveolar type II cells. Am J Physiol Lung Cell Mol Physiol 2004, 286(6):LI 293-LI30I.

21. Bernard GR, Artigas A, Brigham KL, Carlet J, Falke K, Hudson L, Lamy M, LeGall JR, Morris A, Spragg R: Report of the American-European consensus conference on ARDS: definitions, mechanisms, relevant outcomes and clinical trial coordination. The Consensus Committee. Intensive Care Med 1994, 20(3):225-232.

22. Krafft AE, Duncan BW, Bijwaard KE, Taubenberger JK, Lichy JH: Optimization of the Isolation and Amplification of RNA From Formalin-fixed, Paraffin-embedded Tissue: The Armed Forces Institute of Pathology Experience and Literature Review. Mol Diagn 1997, 2(3):217-230.

23. Godinho SIMA: An animal model of the acute respiratory distress syndrome (ARDS). European Respiratory Journal 2002, 20:486s.

24. Witherden IR, Tetley TD, Rogers DF, Donnelly LE: Isolation and culture of human alveolar type II pneumocytes. In Methods in Molecular Medicine, Volume 56 (book) Volume Chapter II. Human airway inflammation; sampling techniques and analytical protocols: Humana Press Inc., Totawa, New Jersey; 200I:137-146.

25. Zhao D, Zhu BL, Ishikawa T, Quan L, Li DR, Maeda H: Real-time RT-PCR quantitative assays and postmortem degradation profiles of erythropoietin, vascular endothelial growth factor and hypoxia-inducible factor I alpha mRNA transcripts in forensic autopsy materials. Legal medicine (Tokyo, Japan) 2006, 8(2): $132-136$

26. Koyama $S$, Sato E, Haniuda M, Numanami H, Nagai S, Izumi T: Decreased level of vascular endothelial growth factor in bronchoalveolar lavage fluid of normal smokers and patients with pulmonary fibrosis. Am J Respir Crit Care Med 2002, 166(3):382-385

27. Lieto E, Ferraraccio F, Orditura M, Castellano P, Mura AL, Pinto M, Zamboli A, De Vita F, Galizia G: Expression of vascular endothelial growth factor (VEGF) and epidermal growth factor receptor (EGFR) is an independent prognostic indicator of worse outcome in gastric cancer patients. Annals of Surgical Oncology 2008, I (1):69-79.
28. Mura M, Dos Santos CC, Stewart D, Liu M: Vascular endothelial growth factor and related molecules in acute lung injury. $J$ Appl Physiol 2004, 97(5): 1605-1617.

29. Mura M, Han B, Andrade CF, Seth R, Hwang D, Waddell TK, Keshavjee S, Liu M: The early responses of VEGF and its receptors during acute lung injury: implication of VEGF in alveolar epithelial cell survival. Critical care (London, England) 2006, I0(5): RI30

30. Perkins GD, Roberts J, McAuley DF, Armstrong L, Millar A, Gao F, Thickett DR: Regulation of vascular endothelial growth factor bioactivity in patients with acute lung injury. Thorax 2005, 60(2): $153-158$

3I. Shraga-Heled N, Kessler O, Prahst C, Kroll J, Augustin H, Neufeld G: Neuropilin-I and neuropilin-2 enhance VEGF I 2 I stimulated signal transduction by the VEGFR-2 receptor. Faseb J 2007, $21(3): 915-926$

32. Montgomery AB, Stager MA, Carrico CJ, Hudson LD: Causes of mortality in patients with the adult respiratory distress syndrome. Am Rev Respir Dis 1985, I32(3):485-489.

33. Medford AR, Millar AB: Vascular endothelial growth factor (VEGF) in acute lung injury (ALI) and acute respiratory distress syndrome (ARDS): paradox or paradigm? Thorax 2006, $6 I(7): 621-626$.

34. Berse B, Brown LF, Van de WL, Dvorak HF, Senger DR: Vascular permeability factor (vascular endothelial growth factor) gene is expressed differentially in normal tissues, macrophages, and tumors. Mol Biol Cell 1992, 3(2):2II-220.

35. Corne J, Chupp G, Lee CG, Homer RJ, Zhu Z, Chen Q, Ma B, Du Y, Roux F, McArdle J, Waxman AB, Elias JA: IL-I 3 stimulates vascular endothelial cell growth factor and protects against hyperoxic acute lung injury. J Clin Invest 2000, I06(6):783-79I.

36. Compernolle V, Brusselmans K, Acker T, Hoet P, Tjwa M, Beck $H$, Plaisance S, Dor Y, Keshet E, Lupu F, Nemery B, Dewerchin M, Van Veldhoven P, Plate K, Moons L, Collen D, Carmeliet P: Loss of HIF. 2alpha and inhibition of VEGF impair fetal lung maturation, whereas treatment with VEGF prevents fatal respiratory distress in premature mice. Nat Med 2002, 8(7):702-710.

37. Karmpaliotis D, Kosmidou I, Ingenito EP, Hong K, Malhotra A, Sunday $\mathrm{ME}$, Haley KJ: Angiogenic growth factors in the pathophysiology of a murine model of acute lung injury. Am J Physiol Lung Cell Mol Physiol 2002, 283(3):L585-L595.

38. Watkins RH, D'Angio CT, Ryan RM, Patel A, Maniscalco WM: Differential expression of VEGF mRNA splice variants in newborn and adult hyperoxic lung injury. Am J Physiol 1999, 276(5 Pt I):L858-L867.

39. Berthiaume $Y$, Lesur $O$, Dagenais $A$ : Treatment of adult respiratory distress syndrome: plea for rescue therapy of the alveolar epithelium. Thorax 1999, 54(2): 150-160.

40. Ohwada A, Yoshioka Y, Iwabuchi K, Nagaoka I, Dambara T, Fukuchi $Y$ : VEGF regulates the proliferation of acid-exposed alveolar lining epithelial cells. Thorax 2003, 58(4):328-332.

\begin{tabular}{|l|}
\hline Publish with Bio Med Central and every \\
scientist can read your work free of charge \\
"BioMed Central will be the most significant development for \\
disseminating the results of biomedical research in our lifetime. " \\
Sir Paul Nurse, Cancer Research UK \\
Your research papers will be: \\
• available free of charge to the entire biomedical community \\
• peer reviewed and published immediately upon acceptance \\
• cited in PubMed and archived on PubMed Central \\
• yours - you keep the copyright \\
Submit your manuscript here: \\
http://www.biomedcentral.com/info/publishing_adv.asp
\end{tabular}

